\title{
Jedi-1 and MEGF10 Signal Engulfment of Apoptotic Neurons through the Tyrosine Kinase Syk
}

\author{
Jami L. Scheib, Chelsea S. Sullivan, and Bruce D. Carter \\ Department of Biochemistry, the Vanderbilt Brain Institute, and the Kennedy Center for Human Development, Vanderbilt University School of Medicine, \\ Nashville, Tennessee 37232
}

During the development of the peripheral nervous system there is extensive apoptosis, and these neuronal corpses need to be cleared to prevent an inflammatory response. Recently, Jedi-1 and MEGF10, both expressed in glial precursor cells, were identified in mouse as having an essential role in this phagocytosis (Wu et al., 2009); however, the mechanisms by which they promote engulfment remained unknown. Both Jedi-1 and MEGF10 are homologous to the Drosophila melanogaster receptor Draper, which mediates engulfment through activation of the tyrosine kinase Shark. Here, we identify Syk, the mammalian homolog of Shark, as a signal transducer for both Jedi-1 and MEGF10. Syk interacted with each receptor independently through the immunoreceptor tyrosine-based activation motifs (ITAMs) in their intracellular domains. The interaction was enhanced by phosphorylation of the tyrosines in the ITAMs by Src family kinases (SFKs). Jedi association with Syk and activation of the kinase was also induced by exposure to dead cells. Expression of either Jedi-1 or MEGF10 in HeLa cells facilitated engulfment of carboxylated microspheres to a similar extent, and there was no additive effect when they were coexpressed. Mutation of the ITAM tyrosines of Jedi-1 and MEGF10 prevented engulfment. The SFK inhibitor PP2 or a selective Syk inhibitor (BAY 61-3606) also blocked engulfment. Similarly, in cocultures of glial precursors and dying sensory neurons from embryonic mice, addition of PP2 or knock down of endogenous Syk decreased the phagocytosis of apoptotic neurons. These results indicate that both Jedi-1 and MEGF10 can mediate phagocytosis independently through the recruitment of Syk.

\section{Introduction}

Programmed cell death is a normal part of development for all metazoans. During the embryological formation of the mammalian peripheral nervous system (PNS), $\sim 50 \%$ of the neurons generated are ultimately eliminated through apoptosis (Buss et al., 2006). Although much is known about the regulation of this naturally occurring cell death, very little is known about how the abundance of dead neurons is removed in the PNS. The clearance of apoptotic neurons is a critical step in preventing secondary necrosis and inflammation, which is thought to eventually lead to autoimmunity and the associated peripheral neuropathy (Elliott and Ravichandran, 2010; Nagata et al., 2010).

We previously reported that satellite glial cell precursors are the primary phagocytic cells for apoptotic corpse removal in developing dorsal root ganglia (DRGs). Moreover, we found that Jedi-1, a novel engulfment receptor, and MEGF10, a purported engulfment receptor (Hamon et al., 2006), are both expressed in glial precursor cells and involved in engulfing the apoptotic neurons (Wu et al., 2009). How Jedi-1 and MEGF10 transduce their

\footnotetext{
Received Dec. 29, 2011; revised July 14, 2012; accepted July 25, 2012.

Author contributions: J.L.S. and B.D.C. designed research; J.L.S. and C.S.S. performed research; J.L.S., C.S.S., and B.D.C. analyzed data; J.L.S. and B.D.C. wrote the paper.

This work was supported by the National Institutes of Health Grant NS064278 (to B.D.C.) and T32 DK0563 (to

J.L.S.). We thank Hyun Jeong Jin and Rajan Dang for technical assistance.

The authors declare no competing financial interests.

Correspondence should be addressed to Bruce D. Carter, Vanderbilt School of Medicine, 625 Light Hall, Nashville, TN 37232. E-mail: bruce.carter@vanderbilt.edu.

DOI:10.1523/JNEUROSCI.6350-11.2012

Copyright $\odot 2012$ the authors $\quad 0270-6474 / 12 / 3213022-10 \$ 15.00 / 0$
}

signals has yet to be determined. Interestingly, the data suggest that Jedi-1 and MEGF10 may function in a common pathway (Wu et al., 2009).

Both Jedi-1 and MEGF10 are homologous to the engulfment receptor CED-1 in Caenorhabditis elegans and Draper in Drosophila. All of these receptors are predicted to contain multiple EGF repeats in the extracellular domain, a single transmembrane domain, and targets for phosphotyrosine binding and $\mathrm{SH} 2$ domain-containing proteins in the intracellular domains. Both CED-1 (Zhou et al., 2001; Su et al., 2002) and Draper (Awasaki et al., 2006) associate with CED-6 (dCed-6 in Drosophila), an intracellular adaptor protein that is required for engulfment but whose function remains to be determined. In addition, Draper mediates its effects through the tyrosine kinase Shark, which associates with an immunoreceptor tyrosine-based activation motif (ITAM) within Draper's intracellular domain following phosphorylation by Src42A (Ziegenfuss et al., 2008). ITAMs are common signaling motifs that are well characterized in immune receptors, such as Fc, B cell, and T cell receptors. Upon receptor activation, the ITAM tyrosines are phosphorylated by Src family kinases, resulting in the recruitment and activation of Syk family kinases, which are homologous to Shark. This family includes Syk and Zap-70 and they bind to phosphorylated ITAMs (Irving et al., 1993; Berton et al., 2005; Underhill and Goodridge, 2007) and activate a wide range of downstream pathways, including modification of the actin-cytoskeleton (Mócsai et al., 2010).

Here, we report that the intracellular domains of Jedi-1 and MEGF10 each contain two ITAMs, which facilitated the binding of each receptor to Syk independently, and the association was 
enhanced by Src family kinase-mediated phosphorylation of the receptors. The interaction with Syk was necessary for each receptor to independently mediate phagocytosis in HeLa cells, and inhibition of Syk in glial cells reduced their engulfment of dead neurons. These results identify Syk as an essential mediator for both Jedi-1 and MEGF10 signaling, which are required for the clearance of apoptotic neurons in the developing PNS.

\section{Materials and Methods}

DNA constructs. Jedi-GFP and MEGF10-GFP construction was described previously (Wu et al., 2009). Jedi-GFP and MEGF10-GFP mutants were obtained by site-directed mutagenesis with PfuUltra HF (Stratagene) PCR, and Dpn1 (New England BioLabs) digestion. Syk-myc, Zap-70-myc, and Lck-F505 were kind gifts from Dr. Arthur Weiss (University of California, San Francisco, CA), and Src-F529 was generously provided by Dr. Steven Hanks (Vanderbilt University, Nashville, TN). Fyn and Lyn were kind gifts from Dr. Clifford Lowell (University of California, San Francisco, CA), and Yes was purchased from Addgene (plasmid no. 18067). LRP-1 expression plasmid was a kind gift from Dr. Dudley Strickland (University of Maryland School of Medicine, Baltimore, MD). To make the Syk shRNA that targets both mouse and human Syk mRNA, the synthetic oligonucleotide $5^{\prime}$-GATC CGAAACCGTGGCTGTGAAAATTTCAAGAGAATTTTCACAGCCACG GTTTTTTTTTACGCGTG-3' and the reverse compliment were annealed and ligated into pSIREN-RetroQ-ZsGreen (Clontech). The scrambled shRNA was in the same vector.

Cell culture and transfection. HEK293 cells and HeLa cells were grown in DMEM with 10\% FBS. Transfections of the cells were carried out with Lipofectamine 2000 (Invitrogen) per the manufacturer's recommendations. Stably transfected cells were selected with $4 \mathrm{mg} / \mathrm{ml} \mathrm{G} 418$.

Immunoprecipitation and Western blot analysis. Transfected cells were harvested in $500 \mu \mathrm{l}$ of NP-40 lysis buffer [ $25 \mathrm{~mm}$ Tris, $137 \mathrm{~mm} \mathrm{NaCl}, 2.7$ mм KCl, $1 \%$ NP-40, 10\% glycerol, 1 mm $\mathrm{Na}_{3} \mathrm{VO}_{4}$, Complete Mini EDTAfree Protease Inhibitor Cocktail tablet (Roche)]. Jedi-GFP, MEGF10GFP, and mutants were immunoprecipitated with anti-GFP (Roche) and Protein A Sepharose (Invitrogen). Western blot analysis was performed using primary antibodies to the myc-tag $(1: 1000 ; 9 B 11$, Cell Signaling Technology), phospho-Syk (1:1000; Y525/Y526, Cell Signaling Technology), phosphotyrosine (1:1000; PY99, Santa Cruz Biotechnology), or $\alpha$-tubulin (1:1000; Calbiochem).

RT-PCR and DRG satellite glia precursor isolation. Reverse transcription, PCR, and the isolation of satellite glial cell precursors from embryonic day (E)13.5 DRG from CD1 mice (Charles River Laboratories) was performed as described previously (Wu et al., 2009). Primer sequences used to detect Src family kinase (SFK) mRNA have been described (Meyn et al., 2005).

Engulfment assays. DRG cocultures and engulfment of apoptotic neuron assays were performed as described by Wu et al. (2009), except that cells were cultured in the presence of nerve growth factor (NGF) for four days before NGF withdrawal. In brief, DRG from E13.5 CD1 mouse embryos of either sex were dissociated, and 50,000 cells plated onto a glass, collagen-coated coverslip in 1:1 UltraCULTURE (BioWhittaker): Neuralbasal medium (Invitrogen) with 3\% fetal bovine serum and N2 and B27 supplements plus $50 \mathrm{ng} / \mathrm{ml} \mathrm{NGF}$. The cells were transfected using Effectene (Qiagen) and the transfected cells were detected using anti-GFP (1:500, Abcam) or anti-myc-tag (1:1000; 9B11,Cell Signaling Technology) and anti-mouse labeled with Alexa Fluor 488 (1:400). The nuclei were detected using TOPRO-3 (Life Technologies). Photomicrographs of z-stacks were taken using a Zeiss LSM 510 inverted confocal microscope (Cell Imaging Shared Resource at Vanderbilt University Medical Center, Nashville, TN), and at least 50 cells were analyzed for each experiment. Any cell with an internalized TOPRO-positive signal, other than its own nucleus, was counted as having phagocytosed an apoptotic body.

For the microsphere engulfment assay, 300,000 HeLa cells were plated on $35 \mathrm{~mm}$ tissue culture plates in DMEM plus 10\% FBS. The following day, cells were transfected with the indicated plasmids using Lipofectamine 2000 (Invitrogen). After 24 h, 50,000 of these cells were plated per well on collagen-coated 8 -well chamber slides. The next day, $2 \mu \mathrm{m}$ carboxylate-modified fluorescent microsphere beads (F-8826, Invitrogen) in PBS with $1 \mathrm{mg} / \mathrm{ml} \mathrm{BSA}$ were incubated with the cells at $37^{\circ} \mathrm{C}$ for $2 \mathrm{~h}$, then the unbound microspheres were removed by PBS rinses and the cells were fixed in $10 \%$ formalin. The cells were then immunostained and imaged with Zeiss LSM 510 inverted confocal microscope. The percentage of transfected cells that had engulfed one or more microspheres was determined for each condition.

To inhibit Syk, $1 \mu \mathrm{M}$ Syk inhibitor IV, BAY 61-3606 (Santa Cruz Biotechnology) was used, and to inhibit Src family kinases, $1 \mu \mathrm{M}$ PP2 (Calbiochem) was added to the cells. In the microsphere engulfment assay depicted in Figure 5, the inhibitors were added to the cell culture medium $1 \mathrm{~h}$ before adding microspheres; these assays were performed in 24-well plates with cells plated on collagen-coated glass coverslips. For engulfment assays with DRG cocultures, inhibitors were added $24 \mathrm{~h}$ after transfection and NGF withdrawal, and the cocultures were fixed $24 \mathrm{~h}$ later.

Stimulation of Jedi-1 by addition of apoptotic cells. Apoptosis of $\mathrm{CHO}$ cells was induced by culturing with $1 \mu \mathrm{M}$ staurosporine (Sigma) overnight. Apoptosis was confirmed by propidium iodide staining. Approximately $7.5 \times 10^{6}$ rinsed apoptotic $\mathrm{CHO}$ cells were added to each $10 \mathrm{~cm}$ plate of confluent HEK293 cells stably expressing Jedi-GFP and transiently expressing Syk-myc. Cells were harvested at indicated time points.

\section{Results}

\section{Jedi-1 and MEGF10 interact with Syk through their ITAMs}

The engulfment of dead neurons by glial precursors was previously reported to involve Jedi-1 and MEGF10 (Wu et al., 2009); however, how these receptors signal and whether they function in a common pathway was not clear. The intracellular domains of Jedi-1 and MEGF10 each contain two potential ITAMs, $\mathrm{YxxIx}_{14} \mathrm{YxxM}$ and $\mathrm{YxxPx}_{8} \mathrm{YxxP} / \mathrm{L}$. Although these ITAMs do not consist of the typical $\mathrm{YxxI} / \mathrm{Lx}_{6-12} \mathrm{YxxI} / \mathrm{L}$ consensus sequence, multiple noncanonical ITAMs have been identified, including those that contain YxxM and YxxP (Lee et al., 1998; Ohtsuka et al., 2004; Underhill and Goodridge, 2007). As can be seen in Figure $1 A$, the first ITAM of Jedi-1 and MEGF10 aligns with the ITAM in Draper. In a number of receptors, the ITAMs associate with soluble tyrosine kinases in the Syk family, specifically Syk or ZAP-70. The ITAM domain in Draper was recently reported to bind to the Drosophila Syk homolog Shark, which was required for Draper-mediated phagocytosis (Ziegenfuss et al., 2008). Therefore, we hypothesized that Jedi-1 and MEGF10 can both promote engulfment through interaction with Syk or ZAP-70 through their ITAMs.

Initially, we focused on the novel receptor Jedi-1 to determine whether it could interact with a Syk family kinase independent of MEGF10. HEK293 cells stably expressing Jedi-GFP were transiently transfected with Syk-myc or Zap-70-myc. Upon immunoprecipitation of Jedi-1, an interaction with Syk, but not Zap-70, was observed (Fig. $1 B$ ).

To determine whether the ITAM motifs of Jedi- 1 are required for Syk binding and engulfment, we made four Jedi-1 constructs with tyrosines mutated to phenylalanines. These mutant constructs include mutation of the first tyrosine (Jedi Y923F) or both tyrosines (Jedi Y923F/Y941F) of the first ITAM, and both tyrosines of the other ITAM (Jedi Y1004F/Y1016F) as well as all four tyrosines of both ITAMs (Jedi Y923F/Y941F; Y1004F/ Y1016F). HEK293 cells stably expressing Jedi-GFP or one of the Jedi-GFP mutants were transiently transfected with Syk-myc, and coimmunoprecipitation (IP) of Syk-myc with the Jedi-GFP proteins was analyzed by Western blot. Mutation of either ITAM, even the single tyrosine mutation (Y923F), markedly reduced Jedi-1 binding to Syk, as did mutation of all four tyrosines, suggesting that both ITAMs are required for optimal interaction with Syk (Fig. 1C). Similar to Jedi-1, MEGF10 was also capable of interacting with Syk, and this association was disrupted by mu- 
A Draper 833 Jedi-1 788 MEGF10 890

Draper 874 Jedi-1 854 MEGF10 970
IAHVHYTHD--------TNPPSWPPHLAVAYSTG-RLDGSDYUMPDVSP------SYSHYYSNPSYHTLSOCSPNPPPPN-------KVPGSOLFVSSOAPERPS MPAVTYTPNMRVINADYTIAETLPHSNGGNANSHYFTNP SYHTLSQCAT PHUNNRDRMTIAKSKNNQLFVNLKNVNPGK
873 853 969

\footnotetext{
Draper 944

Jedi-1 933

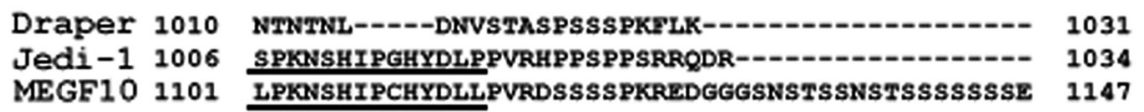

KMANFDQRSTMSTDYGD-----DCNA SGRVGSYSINYNHDLLTKNL-NADRTNPIVYNESL----KEEHVYDEIKHKEGY RAHGRENHVTLPADWKHRREPHERGASHLDRSYSCSYSHRNGPGPFCHKGPISEEGLGASVMSLSS-ENPYATIRDLPSL RGTLVDCTGTLPADWKOGGYLNELGNFGLDRSYMGKSLKDLG----------KNSEYNSSTCSLSSSENPYATIKDPPAL

B

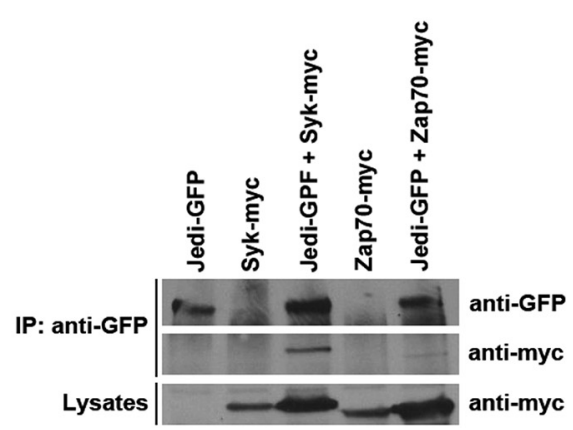

C

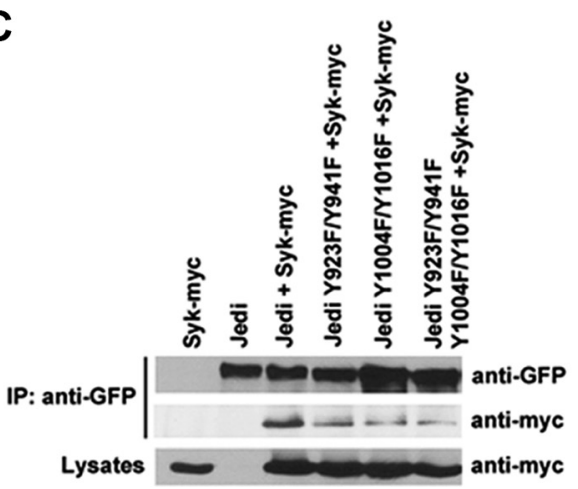

D

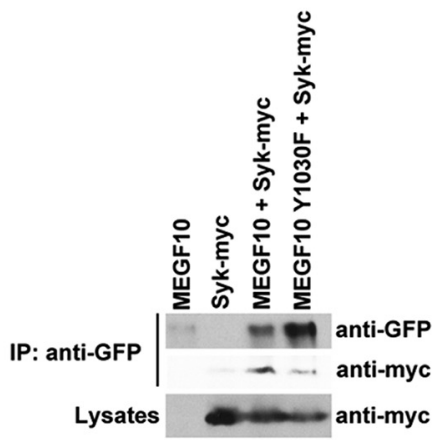

Figure 1. Jedi-1 and MEGF10 contain ITAMs required for Syk interaction. $A$, The intracellular domains of Draper, Jedi-1, and MEGF10 were aligned by NCBI Cobalt Alignment. ITAM motifs are underlined. B, Syk-myc or Zap-70-myc were transfected into HEK293 cells stably expressing Jedi-GFP. Jedi-GFP was immunoprecipitated with anti-GFP, and anti-myc was used to detect Syk-myc and Zap-70-myc. C, Syk-myc was transfected into HEK293 cells stably expressing WT or mutated Jedi-GFP. Anti-GFP was used to immunoprecipitate WT and mutant Jedi-GFP. D, Syk-myc and WT or mutated MEGF10-GFP were transiently transfected in HeLa cells. WT and mutant MEGF10-GFP were immunoprecipitated with anti-GFP.

tation of the first tyrosine in MEGF10's first ITAM, indicating that this receptor also interacts with the kinase through its ITAM domain (Fig. 1D).

To analyze the functional significance of the ITAM domains during engulfment, a microsphere engulfment assay was used. GFP-tagged Jedi-1, MEGF10, or the ITAM mutants were expressed in HeLa cells, and the cells were given $2 \mu \mathrm{m}$ carboxylatemodified fluorescent polystyrene microspheres to engulf for $2 \mathrm{~h}$. Engulfment was analyzed by confocal microscopy (Fig. $2 \mathrm{~A}$ ), and the percentage of transfected cells with at least one microsphere fully internalized, based on a z-stack, was quantified. Low Density Lipoprotein Receptor Related Protein-1 (LRP/CD91), a known phagocytic receptor (Gardai et al., 2005), was used as a positive control. Compared to the GFP transfected control cells, LRP, Jedi-1 and MEGF10 expression significantly increased the engulfment of microspheres (Figs. $2 B, C, 3 A, B$ ). In contrast, none of the various ITAM mutants exhibited any engulfment capability (Figs. 2C, 3B). These results indicate that the ITAM domains are critical for Jedi-1 and MEGF10-mediated engulfment, consistent with their requirement for Syk binding.

To confirm the importance of the ITAMs in mediating engulfment of dead neurons, wild-type Jedi-1 or the Jedi-1 with both ITAMs mutated were expressed in glial cells and their ability to phagocytose apoptotic neurons was scored. The glial cells in dissociated E13.5 dorsal root ganglia (DRG) were transfected with GFP-tagged wild-type or mutant Jedi, then
NGF was removed to induce neuronal apoptosis and confocal microscopy was used to quantify the percentage of GFPpositive glial cells that were engulfing at least one apoptotic body. As we have previously shown (Wu et al., 2009), glia overexpressing Jedi-1 engulfed more apoptotic neurons; however, there was no increase over basal engulfment in the glia overexpressing Jedi-1 with both ITAMs mutated, demonstrating a requirement for the ITAM domains in Jedi-1 for the clearance of apoptotic neurons (Fig. 2D).

Both Jedi-1 and MEGF10 were previously reported to contribute to the engulfment of dead neurons by glial cells and there was no additive effect of over-expressing both receptors or knocking them both down (Wu et al., 2009). These results suggested that Jedi-1 and MEGF10 may be in the same pathway; however, the glial cells express endogenous engulfment receptors, including Jedi-1 and MEGF10, thus assessing the independent function of each was not feasible in this system. Here, we demonstrate that expression of either receptor alone in HeLa cells, which have virtually no basal engulfment capability, facilitated phagocytosis to a similar extent (Fig. $3 A, B$ ). In addition, coexpression of both receptors in HeLa cells resulted in a level of engulfment similar to expression of either receptor alone (Fig. 3B). Taken together, our results suggest that the two receptors act in parallel, but converge in signaling, at least in part, through the downstream kinase Syk. 
A
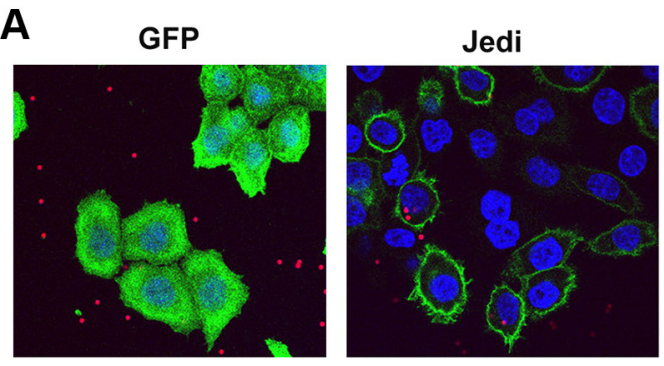

C

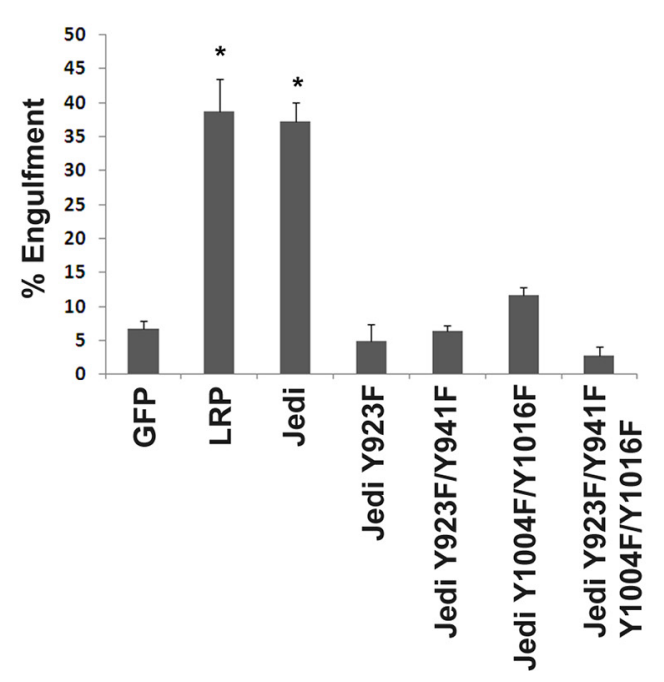

B

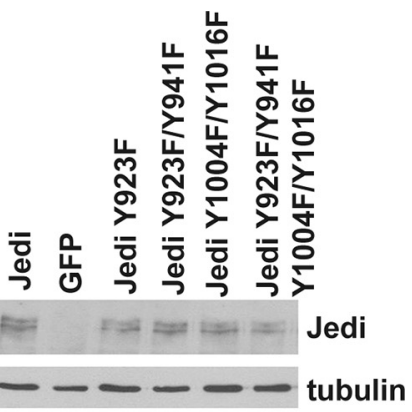

D

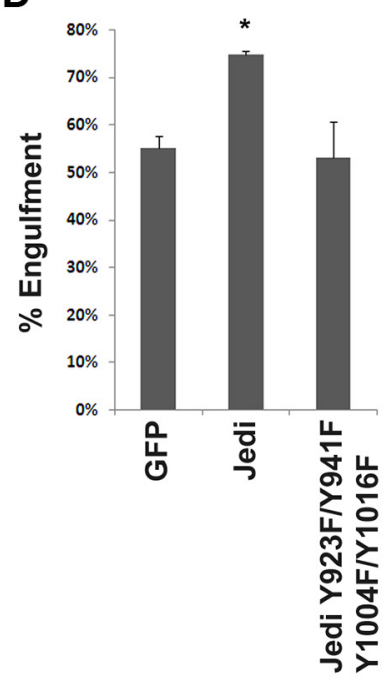

Figure 2. Jedi-1 ITAM tyrosines are required for engulfment. Jedi-GFP, mutants of Jedi-GFP or LRP together with GFP was transfected into HeLa cells and microspheres were added for $2 \mathrm{~h}$, then the cells were rinsed and fixed. $A$, Confocal images are shown with Jedi or GFP-expressing cells (green) containing engulfed microspheres (red). Cell nuclei are shown in blue. $\boldsymbol{B}$, The expression of WT and mutant Jedi-GFP were confirmed by Western blot. $C$, The percentage of HeLa cells, transfected with WT or mutant Jedi or LRP, engulfing at least one microsphere was quantified ( $p=0.0016$ for LRP, $p=0.00009$ for Jedi, $n=3-6$ ). D, GFP, WT Jedi-GFP, or mutant Jedi-GFP was transfected into glial cells in cocultures of E13.5 DRG neurons and glia. Neuronal death was induced by NGF withdrawal, and the percentage of transfected glia engulfing at least one apoptotic body was quantified by confocal analysis $(p=0.048, n=3)$.

\section{Stimulation of Jedi-1 with apoptotic $\mathrm{CHO}$ cells increases Syk binding and activation}

Although the ligand for Jedi-1 is unknown, expression of Jedi-1 confers the ability to bind apoptotic neurons (Wu et al., 2009) and induce phagocytosis of microspheres (Fig. 2); therefore, we hypothesized that Jedi-1 association with Syk and activation of the kinase would be stimulated by addition of apoptotic $\mathrm{CHO}$ cells. To test this hypothesis, CHO cells were killed with staurosporine then added to HEK293 cells expressing Jedi-GFP and Syk-myc for various times. Within $30 \mathrm{~min}$, there was a $94 \%$ increase in Syk association with Jedi-1 by co-IP $(p<0.01, n=3)$ and a $90 \%$ increase in the phosphorylation of Syk $(p<0.05, n=$ 3 ), reflecting activation (Fig. 4), indicating that upon binding an apoptotic cell Jedi-1 recruits and activates Syk.

Syk is essential for Jedi- 1 and MEGF10-mediated engulfment To determine whether Syk was required for engulfment mediated by Jedi-1 or MEGF10, HeLa cells expressing either receptor were treated with the Syk inhibitor, BAY 61-3606, $1 \mathrm{~h}$ before the addition of microspheres. Inhibition of Syk significantly reduced the engulfment of microspheres, consistent with a role for Syk in Jedi-1 and MEGF10 signaling (Figs. $5 A, B)$. (Note that a lower density of microspheres was used for these experiments than for those in Figs. $2 C$ and $3 B$, hence the reduced absolute level of microsphere engulfment).

To investigate the requirement for Syk in the phagocytosis of apoptotic neurons by glial cells, which depends on endogenous Jedi-1 and MEGF10 (Wu et al., 2009), we performed Syk knock-down. After confirming the shRNA could knock-down Syk (Fig. 6A), it was transfected into the glial cells in the cocultures. Interestingly, glia that were transfected with Syk shRNA had a very altered morphology, becoming highly elongated with many thin branches (Fig. 6B), similar to what has been reported for silencing Syk in other cells (Schymeinsky et al., 2006; Bhavsar et al., 2009; Sung et al., 2009). Quantification of the number of transfected glia that were engulfing an apoptotic fragment revealed that Syk knock down significantly reduced engulfment of the apoptotic neurons by $23 \%$ (Fig. $6 C$; $p=0.021, n=3)$. In contrast, overexpressing Syk in the glial cells did not result in any overt morphological changes, but there was a $40 \%$ increase in engulfment (Fig. $6 B, C ; p=0.022, n=4$ ).

To further probe the requirement for Syk in phagocytosis mediated by Jedi-1 and MEGF10 in glial cells, the satellite glial precursors in dissociated DRGs were transfected with GFP, Jedi-1 or MEGF10, then NGF was removed to induce neuronal apoptosis in the presence or absence of the Syk inhibitor. Quantification of the engulfed apoptotic neurons revealed that expression of Jedi or MEGF10 enhanced engulfment, as previously reported $(\mathrm{Wu}$ et al., 2009), but the enhancement was prevented by Syk inhibition (Fig. 6D).

\section{Jedi-1 and MEGF10 are phosphorylated by Src Family} Kinases, which increases Syk interaction

The binding of Syk family kinases to ITAMs is typically through the SH2 domain of the kinase interacting with the ITAM tyrosines, which are phosphorylated by Src Family Kinases (SFKs) in response to activation of immune receptors such as the B- and T-cell receptor (Geahlen, 2009; Love and Hayes, 2010). In addition, some evidence suggests Syk tyrosine kinases themselves may also play a role in phosphorylation of ITAMs (Latour et al., 1997; Zoller et al., 1997). To determine whether Syk can phosphorylate Jedi-1, HEK293 cells stably expressing Jedi-GFP were transfected with Syk. There was no apparent increase in tyrosine phosphorylation of Jedi-1 when coexpressed with Syk (Fig. 7A). Therefore, we searched for SFKs that could phosphorylate Jedi-1 and/or MEGF10 by determining which members of the kinase family are expressed in glia of E13.5 mouse DRG, during the peak time of neuron death in development. RT-PCR of RNA from cultured E13.5 glial precursors revealed expression of 4 SFKs: Src, Fyn, Lyn, and Yes (data not shown). Unlike Syk, when SFKs (Fyn, Lck, Lyn, Src, or Yes) were expressed in HEK293 cells with Jedi-GFP, there was an increase in Jedi-1 tyrosine phosphorylation (Fig. 
A
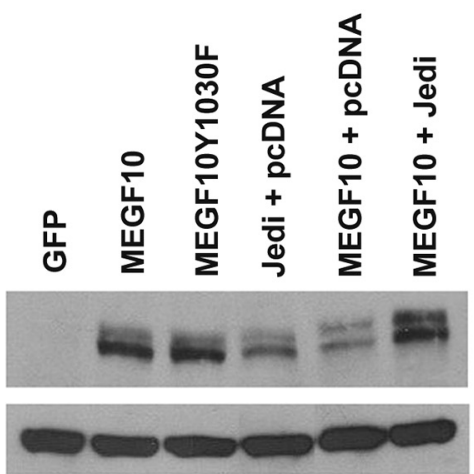

anti-GFP

anti-tubulin

B

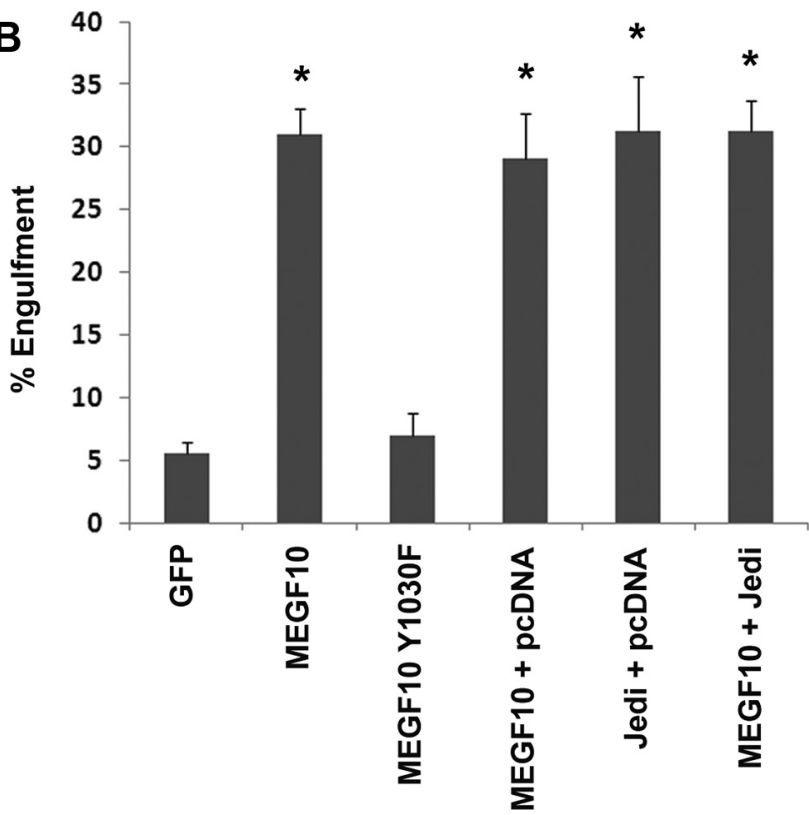

Figure 3. MEGF10-mediated engulfment requires its ITAM domain and is not additive with Jedi. $\boldsymbol{A}$, Jedi and MEGF10 were transfected alone or together, or mutant MEGF10 was transfected, into HeLa cells. Expression levels were analyzed by Western blot. $\boldsymbol{B}$, Microspheres were added, and the percentage of transfected cells engulfing at least one microsphere was quantified by confocal microscopy (MEGF10, $p=0.0003$; MEGF10 + pcDNA3, $p=0.0034$; Jedi + pCDNA3, $p=0.0045$; Jedi + MEGF10, $p=0.0005, n=3$ ).

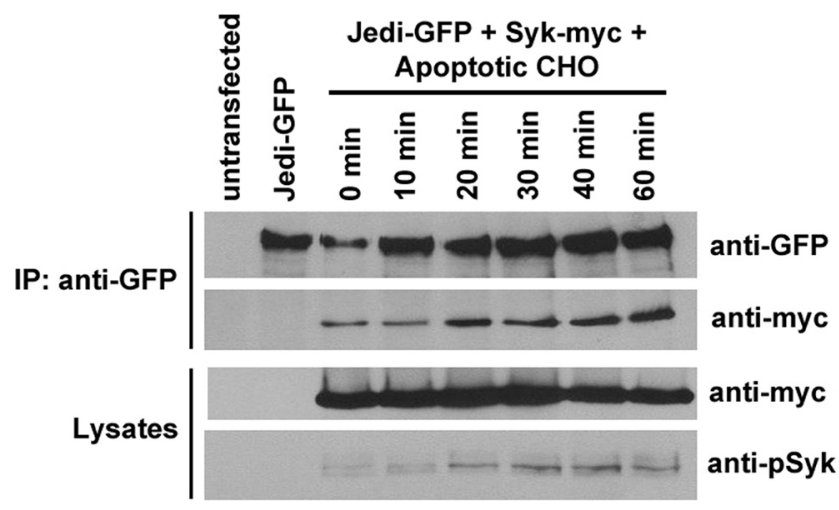

Figure 4. Syk associates with Jedi- 1 and becomes active upon stimulation with apoptotic CH0 cells. HEK293 cells stably expressing Jedi-GFP were transfected with Syk-myc and $24 \mathrm{~h}$ later, apoptotic $\mathrm{CHO}$ cells were added for the indicated times. Coimmunoprecipitation of Sykmyc with Jedi-GFP was detected with anti-myc. Phospho-Syk was detected in the lysates by Western blotting with a phospho-Syk-specific antibody.

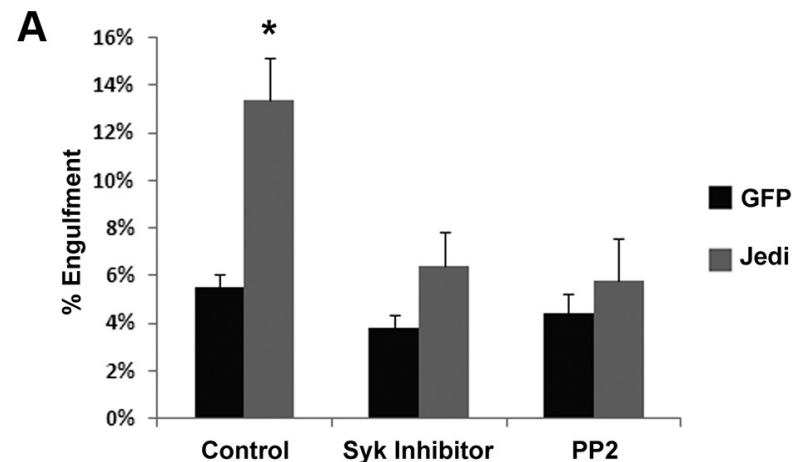

B

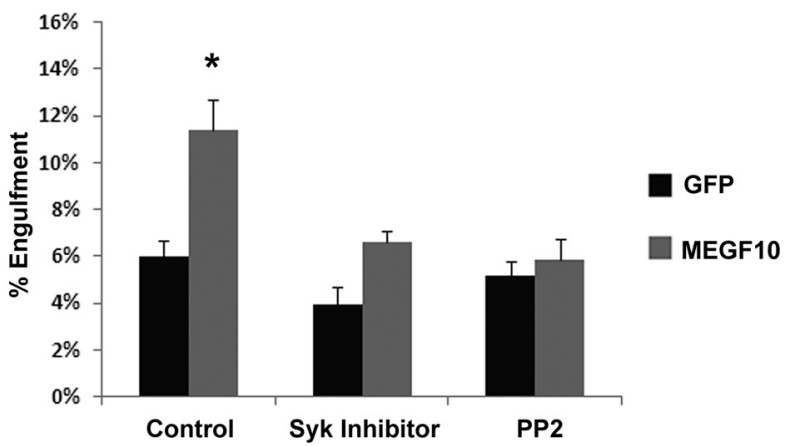

Figure 5. Syk and SFKs are required for Jedi-1 or MEGF10-mediated engulfment. $\boldsymbol{A}$ and $\boldsymbol{B}$, HeLa cells were transfected with GFP, Jedi-GFP, or MEGF10-GFP, and after 48 h, $1 \mu \mathrm{m}$ Syk inhibitor (BAY 61-3606) or $1 \mu \mathrm{M} \mathrm{PP2}$ was added to the HeLa cells $1 \mathrm{~h}$ before addition of microspheres for $2 \mathrm{~h}$. Cells were rinsed, fixed, and engulfment of microspheres was detected by confocal microscopy and quantified. The Syk inhibitor significantly reduced Jedi-mediated $(p=0.015, n=5)$ and MEGF10-mediated ( $p=0.026, n=3)$ engulfment. Similarly, PP2 significantly decreased the engulfment mediated by Jedi $(p=0.016, n=5)$ or MEGF10 ( $p=$ $0.024, n=3)$.

7 B, C). When Fyn, Lck, Lyn, or Src, but not Yes, were expressed with MEGF10, there was also an increase in tyrosine phosphorylation (Fig. $7 B, D$ ).

To determine whether SFKs exhibit selectivity for the ITAM tyrosines in Jedi-1, the kinase Fyn was coexpressed with Jedi-GFP or the ITAM mutants shown in Figure 1C (Fyn was chosen due to its relatively high expression level in the glial cells). Interestingly, mutation of the tyrosines in either ITAM dramatically reduced the phosphorylation of Jedi-1 and no phospho-tyrosine was detected if all 4 residues were mutated, suggesting that both ITAMs are essential for maximum phosphorylation of Jedi-1 (Fig. 7C). The requirement for both ITAMs for maximal phosphorylation of Jedi-1 is in agreement with the results in Figure 1, that both ITAMs are required for maximal Syk association. Similarly, mutation of the first ITAM tyrosine of MEGF10 prevented phosphorylation of MEGF10 by Fyn (Fig. 7D).

To investigate whether phosphorylation of Jedi-1 or MEGF10 enhanced the association with Syk, HEK293 cells expressing JediGFP or MEGF10-GFP were transfected with Syk and Fyn, Lck, Lyn, Src, or Yes. In the cells transfected with Jedi- 1 and Fyn, Lck, Lyn, or Yes, there was an increase in the co-IP between Syk and Jedi-1, but Src transfection did not have an effect (Fig. 7E). When the cells were transfected with MEGF10 and Fyn, Lck, or Lyn, there was an increase in the co-IP between Syk and MEGF10, but Src and Yes had no effect (Fig. $7 F$ ). These results indicate that phosphorylation of Jedi-1 or MEGF10 by Fyn, Lck, or Lyn increases Syk binding, but Src does not. Interestingly, Yes phosphorlylated Jedi-1 and increased Syk binding, but did not phosphorylate MEGF10 or increase Syk binding, indicating the potential for 
A

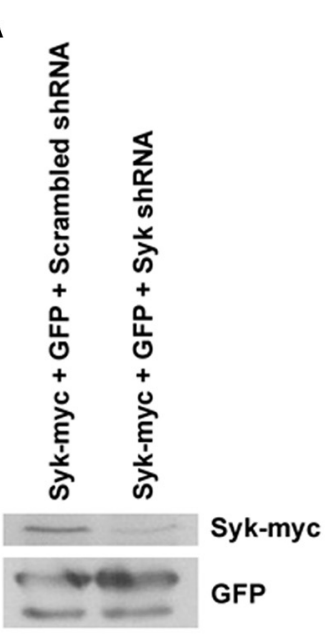

C

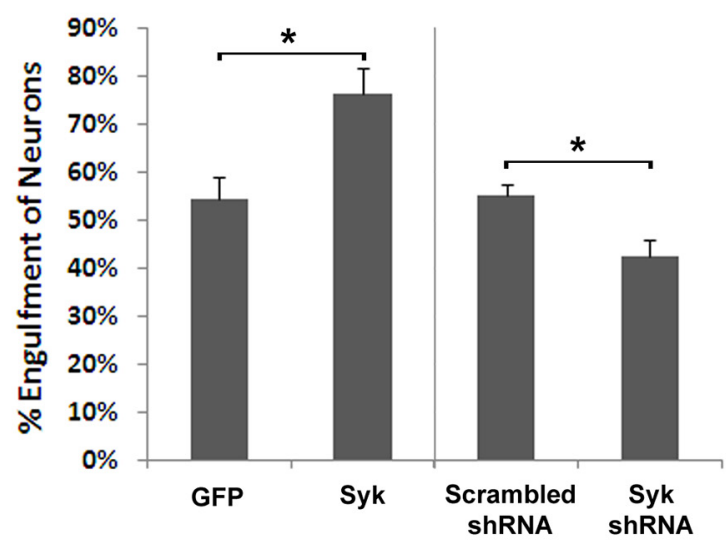

D

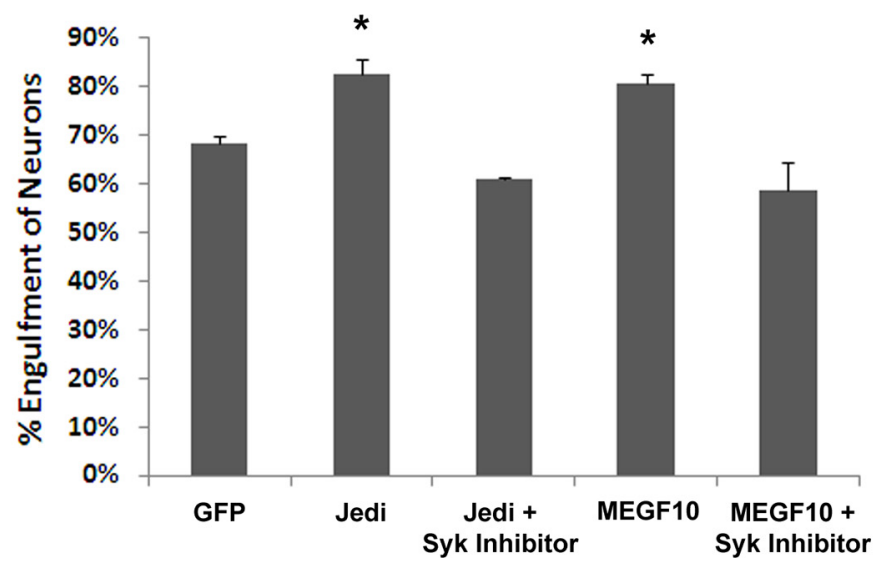

Figure 6. Altered Syk expression or inhibition affects the engulfment of neurons by glial precursors. $\boldsymbol{A}$, Syk-myc, GFP, and scrambled or Syk shRNA were transfected into HEK293 cells. Lysates were immunoblotted with anti-myc and anti-GFP. B, Confocal images depicting cocultures of E13.5 DRG neurons and glial precursor cells transfected with GFP and scrambled or Syk shRNA, GFP or Syk-myc. Neuronal death was induced by removing NGF for $48 \mathrm{~h}$. Transfected glia are depicted in green and nuclei in red. $\boldsymbol{C}$, Scrambled or Syk shRNA, and GFP were transfected into glia in cocultures of DRG neurons and glia and the percentage of transfected glia that were engulfing apoptotic neurons was quantified (Syk shRNA, $p=0.021$; Syk over expression, $p=0.022 ; n=4$ ). $\boldsymbol{D}$, Cocultures were transfected with GFP, Jedi-GFP, or MEGF10-GFP, and a Syk inhibitor (BAY 61-3606) was added for the last $24 \mathrm{~h}$. Engulfment of apoptotic bodies was quantified by confocal microscopy. Expression of GFP, Jedi $(p=0.022, n=3)$ or MEGF10 $(p=0.0056, n=3)$ significantly increased engulfment, but this was prevented by treatment with the Syk inhibitor (Jedi, $p=$ 0.0022 ; MEGF10, $p=0.025, n=3$ ). some differential signaling capabilities between these two receptors.

SFKs are essential for Jedi-1 and MEGF10-mediated engulfment

To investigate whether SFKs are required for phagocytosis specifically mediated by Jedi-1 or MEGF10, a SFK inhibitor PP2, was added to the HeLa microsphere engulfment assay $1 \mathrm{~h}$ before addition of microspheres. Although HeLa cells expressing Jedi-1 or MEGF10 had significantly greater engulfment than control cells, this increase was prevented when the cells were treated with the SFK inhibitor PP2 (Figs. 5A,B).

The importance of SFKs in apoptotic neuron engulfment by glial cells was also investigated. GFP or Fyn was transfected into glia in DRG cocultures, neuronal apoptosis was induced by NGF withdrawal and the percentage of transfected glia engulfing at least one apoptotic body was quantified. Fyn over expression significantly increased engulfment compared to the GFP control cells by $42 \%$ ( $p=0.0053$, $n=3$ ). In contrast, addition of PP2, which inhibits all SFKs, to the cocultures resulted in a significant reduction in engulfment by $32 \%(p=0.0083, n=3)$. These data support the involvement of SFKs in the engulfment of apoptotic neurons by glial precursors, which is a Jedi-1 and MEGF10 dependent process ( $\mathrm{Wu}$ et al., 2009).

Taken together, the data suggest a model where the binding of apoptotic neurons to either Jedi-1 or MEGF10 induces phosphorylation of their ITAM tyrosines by SFKs, which promotes Syk binding to each receptor independently, leading to engulfment of apoptotic neurons (Fig. 8).

\section{Discussion}

Clearing the apoptotic cells that are generated during normal development is essential to prevent secondary necrosis and the breakdown of the cell membrane, which results in the release of intracellular contents that can be toxic or immunogenic. Although the effects of inhibiting the removal of cell corpses specifically in the nervous system has not been studied, there is strong evidence that broadly suppressing the proper clearance of apoptotic cells in mice leads to the development of autoimmunity (Elliott and Ravichandran, 2010). Furthermore, defects in the phagocytic ability of macrophages have been linked to autoimmune disease in humans (Hodge et al., 2003; Ren et al., 2003). Interestingly, many patients with autoim- 
A
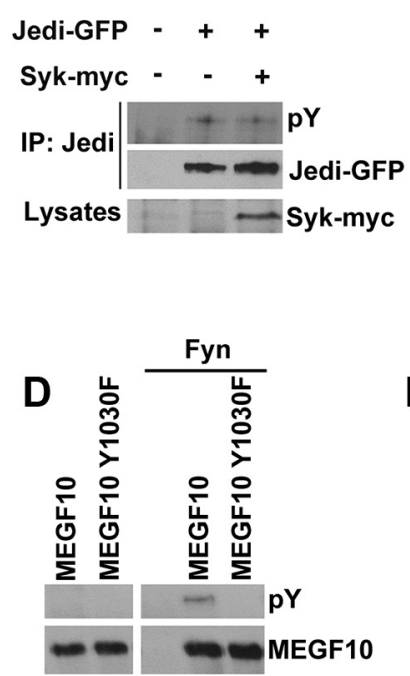

B

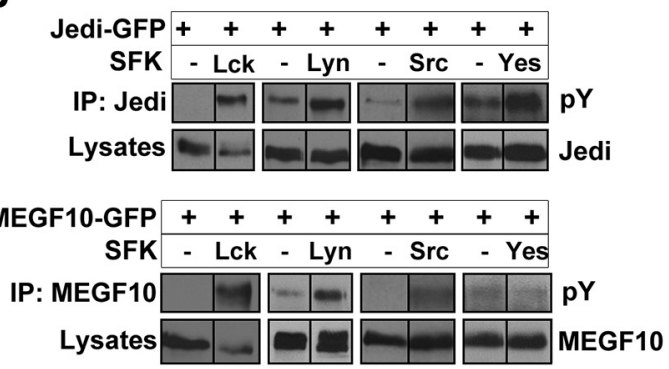

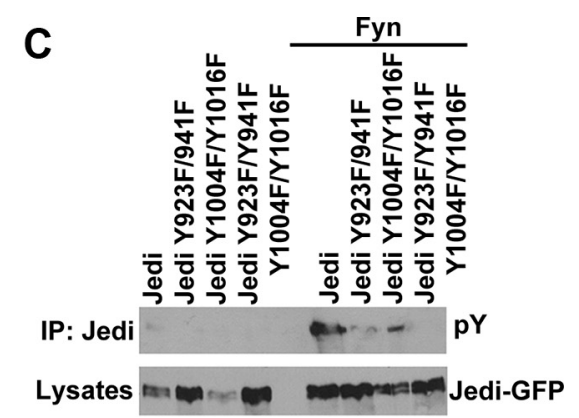

E

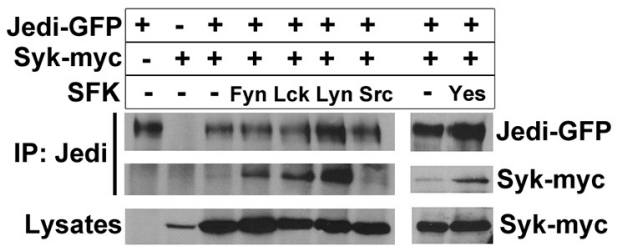

$\mathbf{F}$

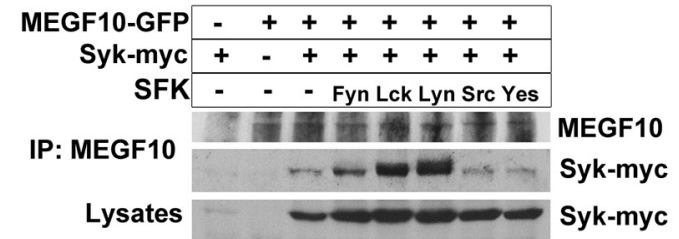

Figure 7. SFKs phosphorylate Jedi-1 and MEGF10 at ITAM tyrosines, increasing Syk binding. A, HEK293 cells stably expressing Jedi-GFP were untransfected or transfected with Syk-myc. Jedi-GFP immunoprecipitates were immunoblotted with anti-phosphoTyrosine, anti-GFP and anti-myc. B, HEK293 cells were transfected with Jedi-GFP or MEGF10-GFP and Lck, Lyn, Src, or Yes. Jedi-GFP or MEGF10-GFP were immunoprecipitated with anti-GFP and immunoblotted with anti-phophotyrosine. (The images for each kinase and its control are from the same blot, but not always from adjacent lanes. The lanes were put next to each other for the figure). C, D, HEK293 cells expressing WT or mutant Jedi-GFP, or WT or mutant MEGF10-GFP, were transfected with Fyn. Jedi-GFP or MEGF10-GFP was immunoprecipitated and the precipitates were immunoblotted with anti-phosphoTyrosine and anti-GFP. $E, \boldsymbol{F}$, HEK293 cells stably expressing Jedi-GFP or MEGF10-GFP were transfected with Syk-myc and Fyn, Lck, Lyn, Src, or Yes. Jedi-GFP or MEGF10-GFP was immunoprecipitated with anti-GFP and the precipitates were immunoblotted with anti-phosphoTyrosine, anti-GFP and anti-myc.

mune disorders exhibit neurological symptoms; for example, $\sim 25 \%$ of patients with Sjogren's syndrome, a systemic autoimmune disease, present with sensory neuropathy (Sène et al., 2011). The neuropathy associated with these disorders suggests that, at least in some cases, the failure to clear neurons may contribute to the disease etiology.

Unfortunately, very little is known about how the neuronal corpses are normally eliminated, particularly in the PNS. We recently demonstrated that satellite glial precursors in the developing dorsal root ganglia (DRG) are the primary cell type responsible for eliminating dead neurons (Wu et al., 2009). The role of amateur phagocytes in the nervous system has gained increased attention in the last few years. In addition to microglia, the professional phagocytes in the brain, astrocytes can also ingest damaged neurons (Magnus et al., 2002; Park et al., 2007). In the PNS, Schwann cells are involved in pruning synapses during development (Bishop et al., 2004), and after nerve injury they assist macrophages clearing the debris (Fernandez-Valle et al., 1995). In Drosophila, glia are the primary cell type responsible for removing neuronal corpses during development (Sonnenfeld and Jacobs, 1995) and after injury (MacDonald et al., 2006).

The engulfment of neuronal debris by glial precursors in the developing DRG was reported to involve both MEGF10 and a novel receptor Jedi-1, both homologous to Draper and CED-1 (Wu et al., 2009). However, whether MEGF10 and Jedi-1 could function independently was not known, nor were the mechanisms by which they promote engulfment. It was recently determined that Draper signals for engulfment via its ITAM, which becomes phosphorylated by Src42a and binds Shark, a tyrosine kinase homologous to Syk. Here, we establish that this signaling pathway for Draper is conserved in both mammalian engulfment receptors Jedi-1 and MEGF10. We demonstrate that Jedi-1 and MEGF10 can independently interact with Syk through the ITAMs in the intracellular domain of the receptors and promote phagocytosis.
Syk is a known effector for a number of phagocytic receptors, integrins and immune receptors (Mócsai et al., 2010) and promotes cytoskeletal rearrangement through phosphorylation of a variety targets, including the scaffolding adaptors Linker for activation of $\mathrm{T}$ cells (LAT) and SH2 domain-containing leukocyte protein $65 \mathrm{kDa}$ (SLP-65) (Mócsai et al., 2010; Tohyama and Yamamura, 2009). Furthermore, genetic analysis in C. elegans has established that Rac (ced10 ), a regulator of the actin-cytoskeleton, is downstream of ced-1 (Kinchen et al., 2005). Thus, it is likely that Jedi-1 and MEGF10 mediate the engulfment of apoptotic neurons through Syk-induced reorganization of the cytoskeleton.

Previously, we found that both Jedi-1 and MEGF10 are involved in the engulfment of apoptotic neurons by glial precursors and that over expression of both receptors in the glial cells was not additive relative to over expression of either receptor alone $(\mathrm{Wu}$ et al., 2009). These results suggested that Jedi-1 and MEGF10 are in a common pathway or that they converge on a common signaling component. Here, we show that expression of either Jedi-1 or MEGF10 alone in HeLa cells was sufficient to reconstitute engulfment equivalent to the coexpression of both receptors, indicating that the two proteins are most likely not in the same pathway, since they were able to function independent of each other. Furthermore, we identify Syk as a key signaling protein for both receptors, suggesting that Jedi-1 and MEGF10 converge on Syk for their action. Nevertheless, it is likely that there remain other signaling pathways uniquely activated by each receptor, since over expression of each protein in the glial precursors resulted in somewhat different morphologies: Jedi-1 expression resulted in long cell processes, while MEGF10 produced more vacuole-like structures (Wu et al., 2009). What signaling mechanisms account for these phenotypes remains to be determined.

The involvement of multiple engulfment receptors appears to be the norm for phagocytosis. Engulfment of dead cells by macrophages involves multiple receptors and phosphatidyl- 


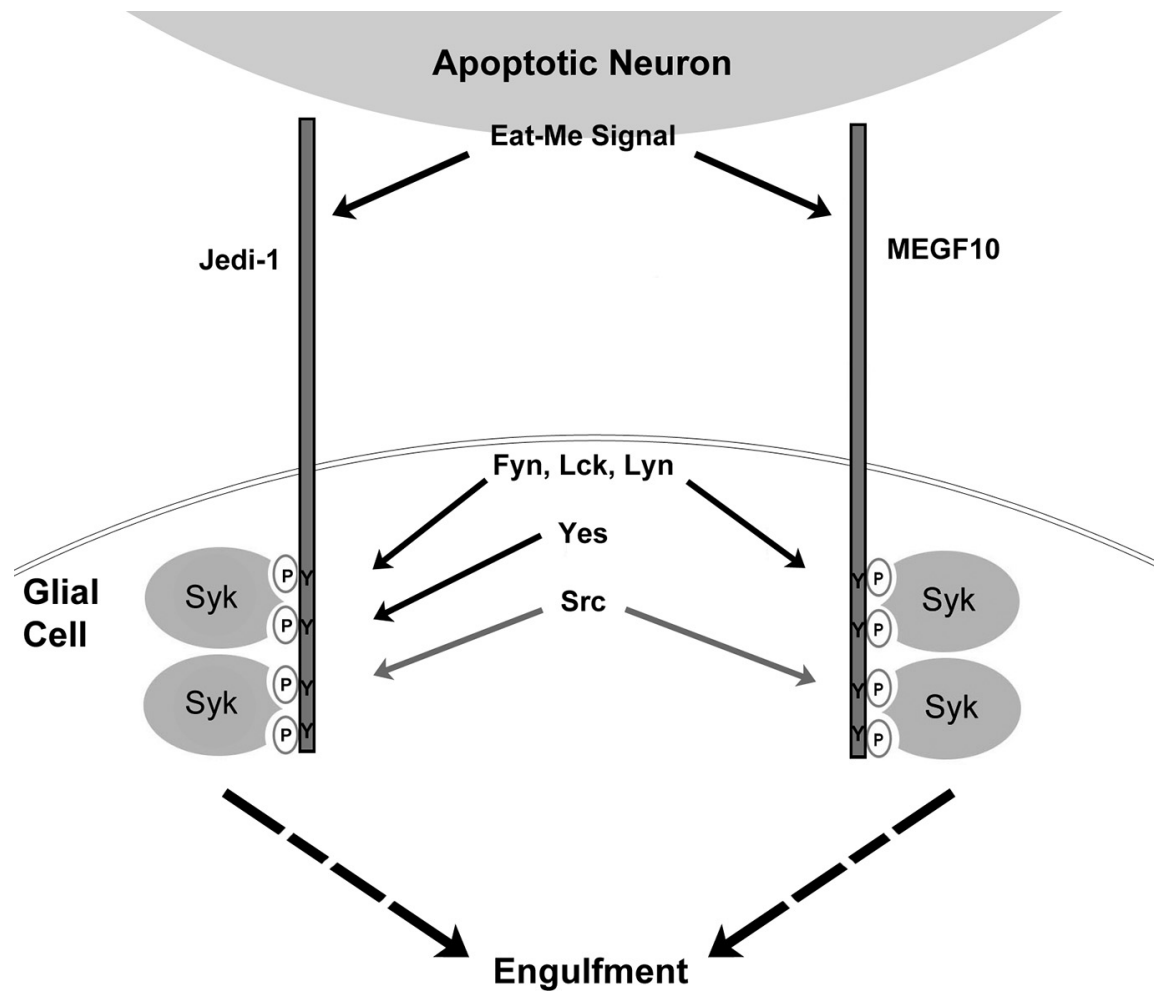

Figure 8. Jedi-1 and MEGF10 independently signal engulfment via SFKs and Syk. When Jedi-1 and MEGF10 are stimulated by apoptotic cells, the SFKs Fyn, Lck, Lyn, and Yes phosphorylate the ITAM tyrosines of Jedi-1, and Fyn, Lck, and Lyn phosphorylate the ITAM tyrosines of MEGF10, resulting in increased Syk interaction. Src can phosphorylate the ITAM tyrosines of Jedi-1 and MEGF10, but it does not increase Syk binding. The stoichiometry of Syk binding to the receptors is not known, but mutation of a single ITAM tyrosine markedly reduced the interaction. Syk association with Jedi- 1 and MEGF10 leads to engulfment of apoptotic neurons by glial cells.

serine binding proteins in what has been termed the "engulfment synapse" (Lauber et al., 2004; Ravichandran and Lorenz, 2007). Several phagocytic receptors mediate engulfment through ITAM-dependent recruitment of Syk or Zap-70 (Tomasello et al., 2000; Colonna, 2003; Mócsai et al., 2004; Linnartz et al., 2010). How all of these receptors uniquely contribute to the phagocytic process is not well understood. Our findings suggest that engulfment by amateur phagocytes is also a multireceptor process involving the tyrosine kinase Syk.

The association of Jedi- 1 with Syk required both of Jedi-1's ITAMs, since mutation of the tyrosines in either ITAM substantially reduced Syk binding (Fig. 1) and engulfment (Fig. 2). Why both ITAMs are required is not clear; however, the T-cell receptor also recruits Syk through multiple ITAMs (Love and Hayes, 2010). Structural analysis of Syk binding to a dually phosphorylated ITAM peptide revealed that the two SH2 domains of Syk act independently, each binding to one phosphotyrosine in the ITAM (Fütterer et al., 1998). Therefore, interaction with two Syks per Jedi-1 may be required for maximal signaling, or the intracellular domain of the receptor may fold in such a way as to allow one Syk to bind to both ITAMs, with each $\mathrm{SH} 2$ domain interacting with a single phosphotyrosine in each ITAM.

Similar to Shark binding to Draper, the interaction between Syk and Jedi-1 or MEGF10 was enhanced when the ITAMs were phosphorylated by SFKs, specifically Fyn, Lyn or Lck, and engulfment was blocked by the SFK inhibitor PP2. Syk binding to ITAMs in immune receptors, such as the B-cell receptor, is known to be enhanced by SFK phosphorylation (Underhill and
Goodridge, 2007); however, the mechanisms by which the receptors activate SFKs, resulting in phosphorylation of their ITAMs are poorly understood. Recent studies of the T-cell receptor, which involves 10 ITAMs in the full complex, revealed that ligand engagement causes the ITAM tyrosines to become available for SFK phosphorylation (Xu et al., 2008). Whether such translocation occurs for the ITAMs in Jedi-1 or MEGF10 remains to be determined.

It is notable that human Jedi-1 (also called PEAR1) was identified in a screen for proteins phosphorylated upon platelet activation. The phosphorylation of PEAR1 was on the first tyrosine in the first ITAM (mouse Y923) and could be blocked by an inhibitor of $\alpha 2 \mathrm{~b} \beta 3$ integrin (Nanda et al., 2005). Integrins have been reported to mediate engulfment (Hanayama et al., 2002; Akakura et al., 2004; Hsu and $\mathrm{Wu}, 2010$ ) and SFKs are well established downstream signals from these receptors (Abram and Lowell, 2007). Hence, one could speculate that integrins may cooperate with Jedi- 1 and MEGF10 to activate phagocytosis by stimulating SFKs, which phosphorylate the ITAMs of Jedi-1 and MEGF10, allowing for recruitment of Syk. Kauskot et al. recently reported that platelet activation induced an interaction between PEAR1 and Fyn or Src, but not Syk (Kauskot et al., 2012), suggesting that SFK phosphorylation of the receptor alone is not sufficient to trigger engulfment and that binding to a ligand on an apoptotic cell is required for PEAR1/Jedi-1 to be fully capable of initiating the phagocytic process.

The ligands for Jedi- 1 and MEGF10 expressed by dead neurons remain to be identified; however, it may involve phosphatidylserine (PS), a well established "eat me" signal. Jedi-1 and MEGF10 are homologous to CED-1, which has been suggested to recognize this phospholipid (Venegas and Zhou, 2007), and when Jedi-1 lacking the intracellular domain was expressed in $C$. elegans, it accumulated around apoptotic cells and prevented their engulfment, suggesting that the extracellular domain of Jedi-1 recognized the nematode engulfment ligand (Wu et al., 2009). In addition, we found that Jedi- 1 and MEGF10 mediated the engulfment of carboxylated microspheres (Figs. 2, 3), which mimic charged membrane molecules such as PS. However, Jedi-1 and MEGF10 are also homologous to Draper, which does not depend on PS (Manaka et al., 2004) but has been suggested to recognize Pretaporter, a protein usually found in the endoplasmic reticulum (Kuraishi et al., 2009).

The results presented here demonstrate a remarkable conservation of the phagocytic mechanisms from Drosophila to mammals. Like Draper, Jedi-1 and MEGF10 are expressed by glia and signal engulfment of apoptotic neurons through SFK phosphorylation of the ITAM domains in the receptors, resulting in the recruitment of Syk. Draper plays a key role in developmental axon pruning and clearance of apoptotic cells after injury, as well as in development (Freeman et al., 2003; Awasaki et al., 2006; 
MacDonald et al., 2006). It will be interesting to determine whether Jedi-1 and MEGF10 also function in such capacities and if disruption of these phagocytic processes leads to pathologies such as auto-immunity.

\section{References}

Abram CL, Lowell CA (2007) Convergence of immunoreceptor and integrin signaling. Immunol Rev 218:29-44.

Akakura S, Singh S, Spataro M, Akakura R, Kim JI, Albert ML, Birge RB (2004) The opsonin MFG-E8 is a ligand for the alphavbeta5 integrin and triggers DOCK180-dependent Racl activation for the phagocytosis of apoptotic cells. Exp Cell Res 292:403-416.

Awasaki T, Tatsumi R, Takahashi K, Arai K, Nakanishi Y, Ueda R, Ito K (2006) Essential role of the apoptotic cell engulfment genes draper and ced-6 in programmed axon pruning during Drosophila metamorphosis. Neuron 50:855-867.

Berton G, Mócsai A, Lowell CA (2005) Src and Syk kinases: key regulators of phagocytic cell activation. Trends Immunol 26:208-214.

Bhavsar PJ, Vigorito E, Turner M, Ridley AJ (2009) Vav GEFs regulate macrophage morphology and adhesion-induced Rac and Rho activation. Exp Cell Res 315:3345-3358.

Bishop DL, Misgeld T, Walsh MK, Gan WB, Lichtman JW (2004) Axon branch removal at developing synapses by axosome shedding. Neuron 44:651-661.

Buss RR, Sun W, Oppenheim RW (2006) Adaptive roles of programmed cell death during nervous system development. Annu Rev Neurosci 29:1-35.

Colonna M (2003) TREMs in the immune system and beyond. Nat Rev Immunol 3:445-453.

Elliott MR, Ravichandran KS (2010) Clearance of apoptotic cells: implications in health and disease. J Cell Biol 189:1059-1070.

Fernandez-Valle C, Bunge RP, Bunge MB (1995) Schwann cells degrade myelin and proliferate in the absence of macrophages: evidence from in vitro studies of Wallerian degeneration. J Neurocytol 24:667-679.

Freeman MR, Delrow J, Kim J, Johnson E, Doe CQ (2003) Unwrapping glial biology: $\mathrm{Gcm}$ target genes regulating glial development, diversification, and function. Neuron 38:567-580.

Fütterer K, Wong J, Grucza RA, Chan AC, Waksman G (1998) Structural basis for Syk tyrosine kinase ubiquity in signal transduction pathways revealed by the crystal structure of its regulatory $\mathrm{SH} 2$ domains bound to a dually phosphorylated ITAM peptide. J Mol Biol 281:523-537.

Gardai SJ, McPhillips KA, Frasch SC, Janssen WJ, Starefeldt A, MurphyUllrich JE, Bratton DL, Oldenborg PA, Michalak M, Henson PM (2005) Cell-surface calreticulin initiates clearance of viable or apoptotic cells through trans-activation of LRP on the phagocyte. Cell 123:321-334.

Geahlen RL (2009) Syk and pTyr'd: Signaling through the B cell antigen receptor. Biochim Biophys Acta 1793:1115-1127.

Hamon Y, Trompier D, Ma Z, Venegas V, Pophillat M, Mignotte V, Zhou Z, Chimini G (2006) Cooperation between engulfment receptors: the case of ABCA1 and MEGF10. PLoS One 1:e120.

Hanayama R, Tanaka M, Miwa K, Shinohara A, Iwamatsu A, Nagata S (2002) Identification of a factor that links apoptotic cells to phagocytes. Nature 417:182-187.

Hodge SJ, Hodge GL, Reynolds PN, Scicchitano R, Holmes M (2003) Increased production of TGF-beta and apoptosis of T lymphocytes isolated from peripheral blood in COPD. Am J Physiol Lung Cell Mol Physiol 285:L492-L499.

Hsu TY, Wu YC (2010) Engulfment of apoptotic cells in C. elegans is mediated by integrin alpha/SRC signaling. Curr Biol 20:477-486.

Irving BA, Chan AC, Weiss A (1993) Functional characterization of a signal transducing motif present in the $\mathrm{T}$ cell antigen receptor zeta chain. J Exp Med 177:1093-1103.

Kauskot A, Di Michele M, Loyen S, Freson K, Verhamme P, Hoylaerts MF (2012) A novel mechanism of sustained platelet alphaIIbbeta3 activation via PEAR1. Blood 119:4056-4065.

Kinchen JM, Cabello J, Klingele D, Wong K, Feichtinger R, Schnabel H, Schnabel R, Hengartner MO (2005) Two pathways converge at CED-10 to mediate actin rearrangement and corpse removal in C. elegans. Nature 434:93-99.

Kuraishi T, Nakagawa Y, Nagaosa K, Hashimoto Y, Ishimoto T, Moki T, Fujita Y, Nakayama H, Dohmae N, Shiratsuchi A, Yamamoto N, Ueda K, Yamaguchi M, Awasaki T, Nakanishi Y (2009) Pretaporter, a Drosophila protein serving as a ligand for Draper in the phagocytosis of apoptotic cells. EMBO J 28:3868-3878.

Latour S, Fournel M, Veillette A (1997) Regulation of T-cell antigen receptor signalling by Syk tyrosine protein kinase. Mol Cell Biol 17:4434-4441.

Lauber K, Blumenthal SG, Waibel M, Wesselborg S (2004) Clearance of apoptotic cells: getting rid of the corpses. Mol Cell 14:277-287.

Lee H, Guo J, Li M, Choi JK, DeMaria M, Rosenzweig M, Jung JU (1998) Identification of an immunoreceptor tyrosine-based activation motif of K1 transforming protein of Kaposi's sarcoma-associated herpesvirus. Mol Cell Biol 18:5219-5228.

Linnartz B, Wang Y, Neumann H (2010) Microglial immunoreceptor tyrosine-based activation and inhibition motif signaling in neuroinflammation. Int J Alzheimers Dis 2010:587463.

Love PE, Hayes SM (2010) ITAM-mediated signaling by the T-cell antigen receptor. Cold Spring Harb Perspect Biol 2:a002485.

MacDonald JM, Beach MG, Porpiglia E, Sheehan AE, Watts RJ, Freeman MR (2006) The Drosophila cell corpse engulfment receptor Draper mediates glial clearance of severed axons. Neuron 50:869-881.

Magnus T, Chan A, Linker RA, Toyka KV, Gold R (2002) Astrocytes are less efficient in the removal of apoptotic lymphocytes than microglia cells: implications for the role of glial cells in the inflamed central nervous system. J Neuropathol Exp Neurol 61:760-766.

Manaka J, Kuraishi T, Shiratsuchi A, Nakai Y, Higashida H, Henson P, Nakanishi Y (2004) Draper-mediated and phosphatidylserine-independent phagocytosis of apoptotic cells by Drosophila hemocytes/macrophages. J Biol Chem 279:48466-48476.

Meyn MA 3rd, Schreiner SJ, Dumitrescu TP, Nau GJ, Smithgall TE (2005) SRC family kinase activity is required for murine embryonic stem cell growth and differentiation. Mol Pharmacol 68:1320-1330.

Mócsai A, Humphrey MB, Van Ziffle JA, Hu Y, Burghardt A, Spusta SC, Majumdar S, Lanier LL, Lowell CA, Nakamura MC (2004) The immunomodulatory adapter proteins DAP12 and Fc receptor gamma-chain (FcRgamma) regulate development of functional osteoclasts through the Syk tyrosine kinase. Proc Natl Acad Sci U S A 101:6158-6163.

Mócsai A, Ruland J, Tybulewicz VL (2010) The SYK tyrosine kinase: a crucial player in diverse biological functions. Nat Rev Immunol 10:387-402.

Nagata S, Hanayama R, Kawane K (2010) Autoimmunity and the clearance of dead cells. Cell 140:619-630.

Nanda N, Bao M, Lin H, Clauser K, Komuves L, Quertermous T, Conley PB, Phillips DR, Hart MJ (2005) Platelet endothelial aggregation receptor 1 (PEAR1), a novel epidermal growth factor repeat-containing transmembrane receptor, participates in platelet contact-induced activation. J Biol Chem 280:24680-24689.

Ohtsuka M, Arase H, Takeuchi A, Yamasaki S, Shiina R, Suenaga T, Sakurai D, Yokosuka T, Arase N, Iwashima M, Kitamura T, Moriya H, Saito T (2004) NFAM1, an immunoreceptor tyrosine-based activation motifbearing molecule that regulates B cell development and signaling. Proc Natl Acad Sci U S A 101:8126-8131.

Park D, Tosello-Trampont AC, Elliott MR, Lu M, Haney LB, Ma Z, Klibanoy AL, Mandell JW, Ravichandran KS (2007) BAIl is an engulfment receptor for apoptotic cells upstream of the ELMO/Dock180/Rac module. Nature 450:430-434.

Ravichandran KS, Lorenz U (2007) Engulfment of apoptotic cells: signals for a good meal. Nat Rev Immunol 7:964-974.

Ren Y, Tang J, Mok MY, Chan AW, Wu A, Lau CS (2003) Increased apoptotic neutrophils and macrophages and impaired macrophage phagocytic clearance of apoptotic neutrophils in systemic lupus erythematosus. Arthritis Rheum 48:2888-2897.

Schymeinsky J, Sindrilaru A, Frommhold D, Sperandio M, Gerstl R, Then C, Mócsai A, Scharffetter-Kochanek K, Walzog B (2006) The Vav binding site of the non-receptor tyrosine kinase Syk at Tyr 348 is critical for beta2 integrin (CD11/CD18)-mediated neutrophil migration. Blood 108:3919-3927.

Sène D, Jallouli M, Lefaucheur JP, Saadoun D, Costedoat-Chalumeau N, Maisonobe T, Diemert MC, Musset L, Haroche J, Piette JC, Amoura Z, Cacoub P (2011) Peripheral neuropathies associated with primary Sjogren syndrome: immunologic profiles of nonataxic sensory neuropathy and sensorimotor neuropathy. Medicine 90:133-138.

Sonnenfeld MJ, Jacobs JR (1995) Macrophages and glia participate in the removal of apoptotic neurons from the Drosophila embryonic nervous system. J Comp Neurol 359:644-652.

Su HP, Nakada-Tsukui K, Tosello-Trampont AC, Li Y, Bu G, Henson PM, 
Ravichandran KS (2002) Interaction of CED-6/GULP, an adapter protein involved in engulfment of apoptotic cells with CED-1 and CD91/low density lipoprotein receptor-related protein (LRP). J Biol Chem 277:11772-11779.

Sung YM, Xu X, Sun J, Mueller D, Sentissi K, Johnson P, Urbach E, SeillierMoiseiwitsch F, Johnson MD, Mueller SC (2009) Tumor suppressor function of Syk in human MCF10A in vitro and normal mouse mammary epithelium in vivo. PLoS One 4:e7445.

Tohyama Y, Yamamura H (2009) Protein tyrosine kinase, syk: a key player in phagocytic cells. J Biochem 145:267-273.

Tomasello E, Cant C, Bühring HJ, Vély F, André P, Seiffert M, Ullrich A, Vivier E (2000) Association of signal-regulatory proteins beta with KARAP/DAP-12. Eur J Immunol 30:2147-2156.

Underhill DM, Goodridge HS (2007) The many faces of ITAMs. Trends Immunol 28:66-73.

Venegas V, Zhou Z (2007) Two alternative mechanisms that regulate the presentation of apoptotic cell engulfment signal in Caenorhabditis elegans. Mol Biol Cell 18:3180-3192.
Wu HH, Bellmunt E, Scheib JL, Venegas V, Burkert C, Reichardt LF, Zhou Z, Fariñas I, Carter BD (2009) Glial precursors clear sensory neuron corpses during development via Jedi-1, an engulfment receptor. Nat Neurosci 12:1534-1541.

Xu C, Gagnon E, Call ME, Schnell JR, Schwieters CD, Carman CV, Chou JJ, Wucherpfennig KW (2008) Regulation of T cell receptor activation by dynamic membrane binding of the CD3epsilon cytoplasmic tyrosinebased motif. Cell 135:702-713.

Zhou Z, Hartwieg E, Horvitz HR (2001) CED-1 is a transmembrane receptor that mediates cell corpse engulfment in C. elegans. Cell 104:43-56.

Ziegenfuss JS, Biswas R, Avery MA, Hong K, Sheehan AE, Yeung YG, Stanley ER, Freeman MR (2008) Draper-dependent glial phagocytic activity is mediated by Src and Syk family kinase signalling. Nature 453:935-939.

Zoller KE, MacNeil IA, Brugge JS (1997) Protein tyrosine kinases Syk and ZAP-70 display distinct requirements for Src family kinases in immune response receptor signal transduction. J Immunol 158:1650-1659. 